\title{
The effect of a template when constructing individual syllabuses in nursing education - An evaluation of student perspective in a mixed methods intervention study
}

\author{
Dorte Lindstroem Vilstrup ${ }^{1}$, Helle Udsen Nielson ${ }^{2}$, Anne Prip ${ }^{1}$ \\ 1. Metropolitan University College, Copenhagen, Denmark. 2. Herlev Hospital, Herlev, Denmark.
}

Correspondence: Dorte Lindstroem Vilstrup. Address: Metropolitan University College, Copenhagen, Denmark. Email: dlvi@phmetropol.dk

Received: October 9, 2013

DOI : $10.5430 /$ jnep.v4n1p258
Accepted: October 28, $2013 \quad$ Online Published: December 16, 2013

URL: http://dx.doi.org/10.5430/jnep.v4n1p258

\section{Abstract}

Background: The individual syllabus is a mandatory part of clinical teaching in Denmark. The tool has been discussed in various settings throughout the nursing education. A literature search revealed that knowledge of how to work with it is minimal.

Objectives: To clarify and test the potential of the individual syllabus in a clinical setting.

Design: A mixed methods intervention study involving first year nursing students and clinical teachers. The intervention consisted of: 1) design of a template and a precise description, 2) testing of the template and description in the form of baseline and post-intervention questionnaires and a student focus group interview.

Results: By using a template, the students' understanding of the purpose, their perception of the value and their sense of ownership of the individual syllabus are improved. The same results are not seen for the clinical teachers. The results point to the fact that there is potential for improving cooperation between clinical teachers and students concerning the tool. The majority of the clinical teachers, however, did find that the template improved the quality of the individual syllabus.

Conclusion: A template has the potential to translate the curriculum-based learning objectives into practical studies and, thereby, improve the gap between theory and practice. The importance of clinical teachers' effect on the way students work becomes evident. The use of templates and structured tools in a pedagogical context is debatable but should receive more attention in the future.

\section{Key words}

Individual syllabus, Theory/practice gap, Templates for learning, Tools for learning, Translation of learning objectives

\section{I ntroduction}

This article shows that working with a specific part of the portfolio in a structured manner has the potential to enhance student involvement with their own study activities. The individual syllabus is one of the ways to work with a portfolio. The use of portfolios in clinical settings has shown that it can lead to improved knowledge and understanding, greater 
self-awareness and encouragement of reflection. The portfolio may have many forms, often defined as "a collection of evidence that learning has taken place" ${ }^{[1]}$. That is not entirely the case with the individual syllabus because the individual syllabus is the students' way to plan how to cover the curriculum before or in the beginning of their clinical teaching period and is more a plan than an actual evaluation. The individual syllabus is mandatory, outlined in The Ministerial Order on the Bachelor of Science in Nursing ${ }^{[2]}$, which is not the case with other specific tools in the portfolio.

The individual syllabus involves three parties: the student, the clinical teacher and a designated theoretical teacher. In this article, 'clinical teacher' will be used synonymously with mentor or supervising nurse.

Even though the individual syllabus is described in the declaration, the requirements are not elaborated, which has led to many questions from involved parties as to its purpose, its contents, what qualifies it, and whether it is a tool that nursing students actually benefit from or just another failed and untested attempt to connect theory and practice. This also became evident at the beginning of the development project described in this article. Here, literature in any form regarding the individual syllabus was searched for. Additionally websites of all other University Colleges were consulted, and the persons in charge of nursing education at the hospitals in the Capital Region were contacted via email for information about how they introduce and work with the individual syllabus in practice (8 hospitals). This pragmatic approach was chosen, due to the assumption, that the clinical nursing education is influenced by local practices and culture. However, the direct contact offered scarce information and feedback upon the subject. The materials collected from the web search made it clear, that the transparency of the purpose and content of an individualized syllabus were different depending on institution and in general unclear and poorly elaborated. This initial search could be characterized as a qualitative approach with the use of documents as data ${ }^{[3]}$, hence all collected documents were thoroughly read, and formed the final hypothesis of the project.

Due to the collected documents, the purpose of the project changed from a focus on a critical examination and illumination of possible potential to a clarification of the requirements and testing of a specific way of working with the tool.

Upon deciding to work in a very structured way, we considered the schism that learning should be active and socially constructed, but at the same time the individual syllabus is a pedagogical tool determined by contractual arrangements. Such a structural factor can impede the transfer of knowledge ${ }^{[4]}$, and transfer of knowledge can be compromised because the discourses of clinical and theoretical teaching are at odds with each other ${ }^{[5]}$.

However the argument pro a structured approach was, that when students use specific criteria to understand and reach learning objectives, the results are better ${ }^{[6]}$, which might have the potential of creating a more optimal platform for learning and for the integration of theory and practice. A more structured approach may also potentially affect the retention of students because academic counselling and feedback mechanisms have the potential to keep the students in their studies ${ }^{[7]}$.

\section{Method}

\subsection{Intervention}

Three project coordinators were involved in the project: a senior lecturer, a lecturer (the project leader) and a clinical teacher with coordinating responsibilities. The project period was 7 months and ended in 2012. The scope was module 4 solely, due to the fact that these students have not consolidated their individual study habits yet. The primary focus for module 4 is basic nursing, and the ECTS is focused on nursing, hygiene, microbiology and nutrition. The Danish Bachelor Degree in nursing consists of 14 modules, lasts 3.5 years, equivalent to 210 ECTS. Module 4 lasts for 10 weeks. 
Before the actual intervention, the literature and data collected in the initial period of the project were used as inspiration to describe the purpose and content of the individual syllabus in a clearer, more detailed and structured manner in a one-page explanation. Secondly, a template for the individual syllabus was designed. The intention was to create a template that could potentially optimize the focus on content instead of structure. The template was formed by using five headlines in a one-page table reflecting the curriculum: area of focus, learning objectives, methods of study, arrangements and literature. Part of the intervention was a three-hour introduction to the students on the first day of the clinical period. This was conducted by two of the project coordinators and consisted of an introduction to the purpose, structure and minimum expected content of the individual syllabus and the opportunity to work with their personal syllabus in groups. An introduction to the goal and purpose of the project and template was also provided to the clinical teachers with plenty of time for discussion. Not all clinical teachers were present at this meeting, but it was the only time and place possible to meet as many clinical teachers as possible. The intervention was, thus, to test whether a more detailed description and a template would make a difference, primarily for the students.

\subsection{Testing}

There were to different approaches for evaluating the intervention. A quantitative approach in form of pre- and postintervention questionnaires and a qualitative approach, both in form of space for elaboration in the questionnaires but also in the form of a post-intervention focus group interview. Focus group interviews offer the opportunity to articulate tacit knowledge and to create a situation in which the students and the project can benefit from the opportunity to reflect on others' experiences and, in this way, create new knowledge and further reflection ${ }^{[8]}$. The questionnaires offered an opportunity to generalise and to measure specific differences ${ }^{[8]}$. Due to the restricted project period, the questionnaires were not validated, but an uninvolved competent person went through the questionnaires for potential pitfalls. A 4-level Likert scale was used to record the answers. However, for two questions, it was possible to elaborate in a more qualitative manner. The questionnaires were modified for each reply group.

\subsection{Materials}

The questionnaires were sent out to all parties involved - students, clinical teachers and theoretical teachers. As only three out of six theoretical teachers answered and because they were not a part of the intervention, their answers are excluded here, and the focus is on the direct collaboration between clinical teachers and students.

Prior to the intervention, 18 students started module 4 at the hospital, 14 of these students responded (77. $8 \%$ ), median age 22. 5 years with 13 females and 1 male in the group. After the intervention, the response percentage was a bit lower - $60 \%$, 12 students out of 20, median age 21.5 years, all female.

The questionnaires were distributed to the clinical teachers in two different ways. Prior to the intervention, it was given to all teachers in the hospital involved in module 4 and, afterwards, only to the ones who had had students from module 4 in the specific project period. Before the intervention, this consisted of 33 clinical teachers (one of the project coordinators was a part of this group and excluded due to potential bias), and 22 responded (66.67\%). The years of experience in teaching students in a clinical setting varied widely from 1 to 30 years (median: 6.5 years). After the intervention, it was only relevant to conduct the questionnaire with 20 of the clinical teachers, of whom 12 responded (60\%) with median experience of 7.5 years (from 3-16 years).

All module 4 students involved in the intervention were invited to participate in the focus group interview, but only 4 volunteered. The interview was conducted by the project participant who had not been involved with the students. This was to give the students a feeling of being able to speak freely in any way they wished to. The interview was taped and transcribed with the consent of the participants. The transcribed version of the interview was used in the project group in a consensus discussion of the results. Themes were discussed and agreed upon. Afterwards, themes were used to understand and discuss both the quantitative and qualitative data, inspired by Malterud's guidelines for qualitative data ${ }^{[9]}$. 


\subsection{Ethics}

The study is based on informed consent from the Metropolitan University College, the hospital in question, the teachers and the students. All participants were informed of the code of silence.

\section{Results}

The results from the questionnaires and focus group interviews fell into five categories: The clarity of the purpose, the value, the sense of ownership, the importance of cooperation and, finally, the perception of change due to the intervention. The results, both baseline and intervention results, are presented here according to these themes in combination with the qualitative data.

\subsection{Clarity - understanding of the purpose}

The baseline questionnaires showed that it was unclear what the content of the individual syllabus is or should be. All parties were asked how they would characterise the clarity of the purpose of the individual syllabus.

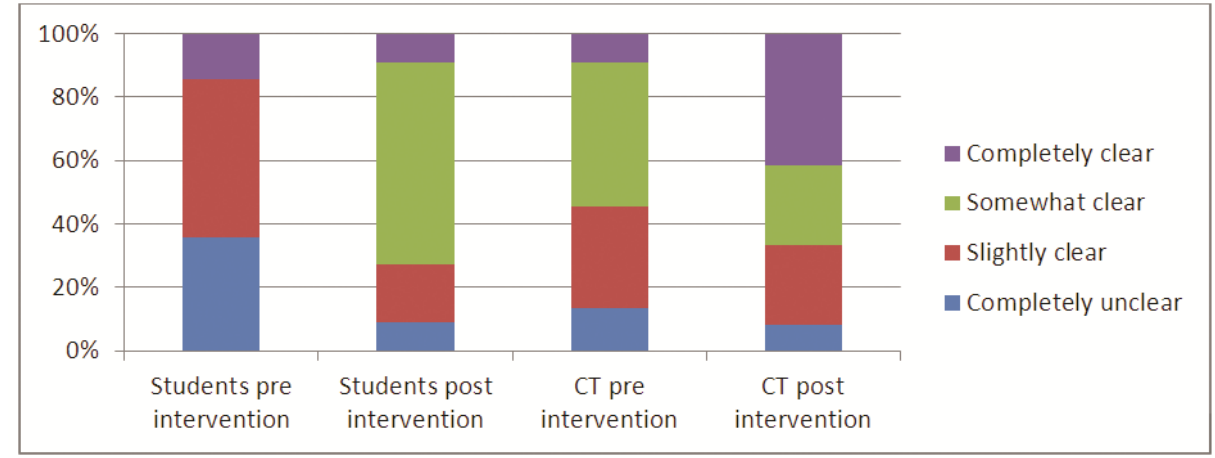

Notes. $\mathrm{CT}=$ Clinical teachers

NB - students post - only 11 answers, 1 respondent didn't answer.

Figure 1. Clarity of the purpose with the individual syllabus

In Figure 1, it is evident that, at baseline, the majority of the students only understand the purpose to a very small extent because only two students evaluate the purpose as being clear; whereas the rest of the respondents answer that it was slightly or completely unclear. The clinical teachers' answers were not entirely similar to those of the students, because 10 respondents actually felt that the purpose is somewhat clear. In the questionnaire, however, it appears in the comments section of the questionnaire that the clinical teachers believe they need to know more about how, when and how much it should be used. They also ask at baseline for a better description of the purpose.

The lack of clarity also became evident in the focus group interview. One student explained how she felt before the introduction to the individual syllabus: "When I heard we should do a syllabus, I became a little panicked. I didn't understand at all what it was for, and I have to make it up - I mean, I didn't even understand the word". In the questionnaire, there was also room to suggest how the approach to the individual syllabus could be improved, and the students wrote: 'more information about what it should contain, and where there are examples and how to use it - it is to forced, the questions are to general / confusing', and one student suggested what we actually ended up doing: 'More guidance in how to do it, maybe before the clinical period, so you can get an idea about how to do it, instead of having to guess and hoping it is the right way'.

After the intervention, there was a remarkable change as to how the clarity of the purpose was perceived. Over half of the students in the post-intervention group categorise their understanding of the purpose as somewhat clear. A change is also seen in the clinical teacher group, the majority of which now answers completely clear. 
The understanding of the purpose of the individual syllabus must to some extent correlate with the degree of instruction and introduction. The introduction was also an issue discussed in the focus group interview in which the need for a detailed introduction is stressed, but it was also discussed when this introduction should take place. Prior to this project, the introduction to the individual syllabus was given at the school in a very broad manner when the students are introduced to the clinical period. This introduction often takes place 4-8 weeks before clinical teaching. In addition, the clinical teachers stress the need for an introduction, and one states in the questionnaire: "Better introduction before praxis is needed!" An introduction to a pedagogical tool is seldom sufficient, often continuous instruction must be required, and the degree of instruction in the clinical setting was, therefore, also examined in the questionnaires. The responses show some lack of instruction. Before the intervention, 78\% of the students believed they received instruction with respect to the individual syllabus from the clinical teacher. After the intervention, the number of students who said they received instruction is remarkably lower, and only $58.3 \%$ of the students state that they received instruction from the clinical teacher. Before the intervention $13.6 \%$ of the teachers do not provide instruction; after the intervention, that number has increased to $25 \%$. The decrease in the number of clinical teachers who provide instruction might be due to the fact that they know there is a general introduction to the individual syllabus. However, it must be seen as a negative side-effect of the intervention. The extent of the concrete instruction varies as well, both before and after the intervention - from 10 minutes to 2 hours (median 30 minutes).

\subsection{Value of the individual syllabus}

Not only is the clarity of a pedagogical tool important but also the value attached to the tool.

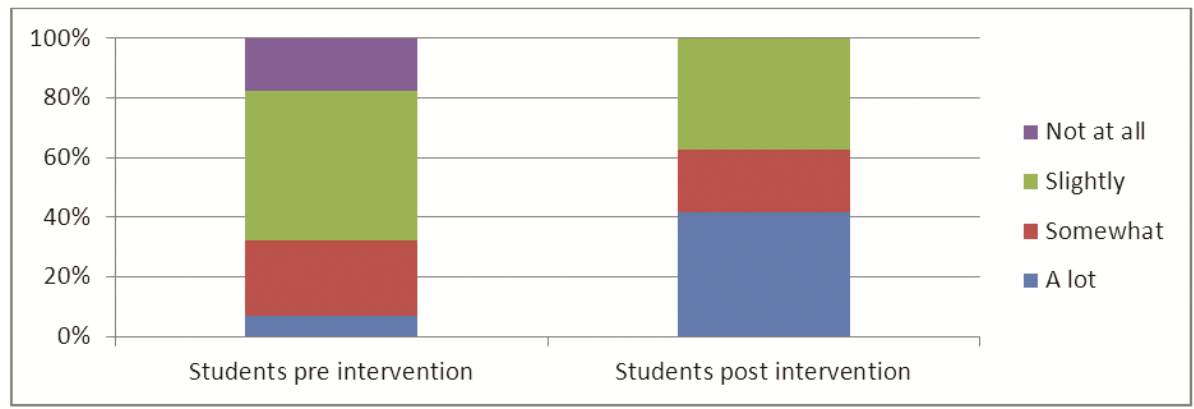

Figure 2. To what degree did the students feel the individual syllabus supported their learning

Without question, the intervention has made a difference as to how the value of the individual syllabus is perceived. After the intervention, as illustrated in the figures above, none of the respondents think it has no value as opposed to before the intervention, and the evaluation of the tool as something that has significantly helped in the learning process has increased remarkably. After the intervention, the students stated in the questionnaires that the syllabus "gives structure throughout the course"; "it has made the work more structured and manageable"; "it has helped to me to read, and I could figure out what opportunities there were and what tasks I could perform". These statements are also evident in the focus group interview. Here, the students explain why the individual syllabus in the form of a template gives the tool more value. One student states that "you understood what it was all about, the learning objectives, when you could link them up to a specific assignment". This sentiment is elaborated by another student: "you were completely surprised, because you could have one area of focus, where six learning objectives were involved". This is particularly important because the learning objectives described in the module description are often difficult for the students, and sometimes also teachers, to understand. The students in focus group define the learning objectives in this way: "they are written in a very particular manner", and "they are very complicated". It, therefore, looks as though the value is increased because a template translates the learning objectives in a way that makes sense to the students.

The template has made it possible for the students to focus on the content of the syllabus instead of the form. They made the template their own when they expanded and added focus areas in order to adjust the learning objectives to the specific 
possibilities in their particular ward and their own preferred way of learning. They did not experience the template as a static document, which could be a disadvantage in using a template. The students in the interview also point to the fact that it is important for the plan to be flexible, because reality does not always match their syllabus. Therefore, the syllabus must be seen as a plan for the whole ten weeks of the clinical period, and then they can swap different objectives around to fit the reality of the ward. The students also point to the fact that it is important not to be too attached to the plan and that it should not cause stress. The clinical teachers did not share the students' positive opinion of the value after the intervention. The change in this group is much less evident.

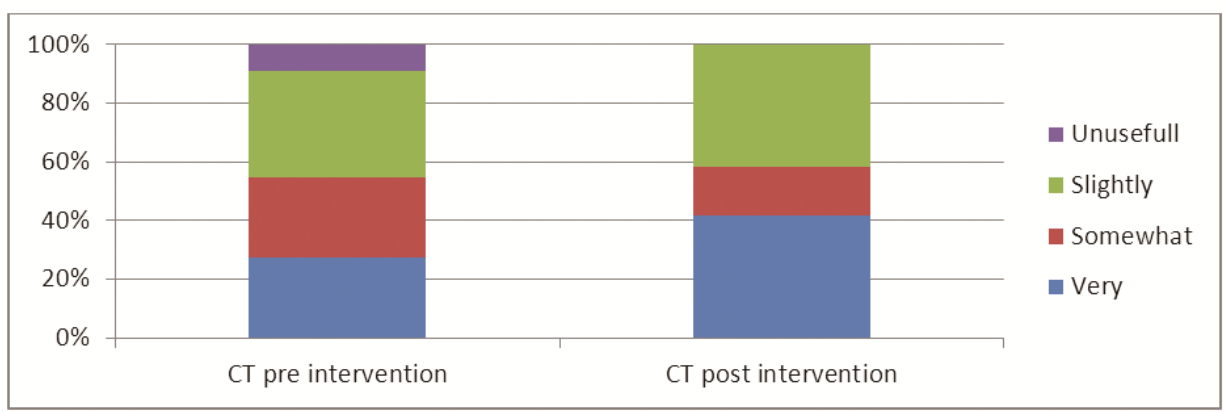

Figure 3. How valuable is the individual syllabus as a learning tool, according to the clinical teachers

The problems the clinical teachers outlined with the individual syllabus prior to the intervention were met with the template and the more detailed description even though the purpose is still not convincingly clear to the clinical teachers, which might also indicate why they grade the value of the tool lower. This could also be connected to the quality of the introduction. One teacher states, post-intervention, that more introduction is needed; another says that the implementation of the individual syllabus is still not sufficient. This, however, does not correspond with the students' evaluation, and this discrepancy could affect the collaboration concerning the tool.

\subsection{Sense of ownership}

The students were asked directly whether they felt the individual syllabuses were their own, whether they felt they were doing it for their own sake.

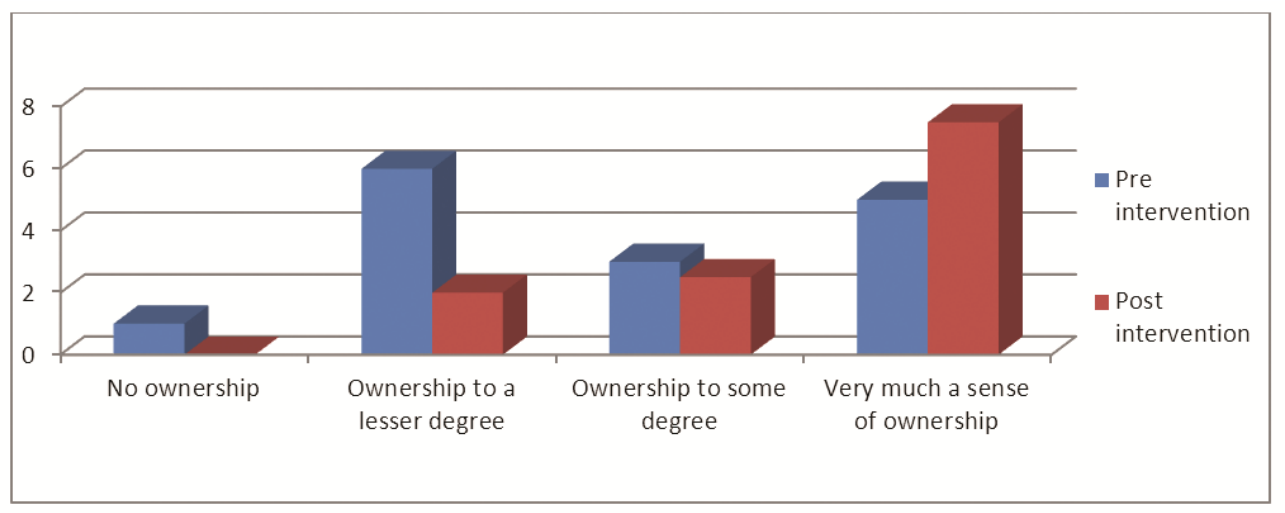

Figure 4. The students' sense of ownership of the individual syllabus

The answer to this question has changed remarkably after the intervention. The sense of ownership has shifted from a category they evaluate as being of minor importance to a category they view as very significant. Prior to the intervention, the questionnaires contained statements such as: "It has only been used to show the teacher" and "it was unclear what you should do with it". Statements such as these are not found after the intervention. 


\subsection{Cooperation on the individual syllabus}

Several questions in the questionnaire were related to cooperation, and it became clear in the interview that this particular element plays a big role for the students. The data show that it is of great importance that there is a common understanding and interest in the individual syllabus, and the clinical teacher was pointed out in particular as an important factor. The students in the interview say that they know it is their responsibility, but it means a lot that the teacher is genuinely interested. One student in the interview states: "if your clinical teacher doesn't find it important, you might not either as a student". In the questionnaires, the students state that "it must be easier to integrate it into the daily life at the ward", and the students ask for "more follow-up from teacher" and "a frequent review of the syllabus together with the teacher would make it more useful". Cooperation between clinical teachers and students was examined as to how often concrete guidance was conducted with respect to the individual syllabus. Both prior to and after the intervention, the answer to this varied widely in the student group - from nil to ten times but, normally, 1-3 times. The clinical teachers state that they provide guidance about 4 times during the module, which is a bit more than the students think they actually get. This confirms that the syllabus is still not used on a weekly basis as intended and might also point to the fact that what is intended as guidance is not always perceived as guidance. In addition, the visibility of the plan plays a role in this context. Students from the interview point to the fact that, if the individual syllabus were visible on a board in the ward, it would engage others in the students' weekly focus area; whereas others found that the syllabus was tucked away and only used during the mandatory study conversations. The data shows that cooperation is central on several levels, when it comes to concrete guidance, visibility and the way it is integrated into teaching practice.

\subsection{Change in quality}

After the intervention, the clinical teachers were asked directly whether they had experienced a change in the quality of the individual syllabus. Two out of three teachers had experienced an improved quality, one teacher no change. The majority (9 out of 12) of the clinical teachers answered that the quality had improved. What aspects the respondents felt were the most important in regards to quality was, unfortunately, not possible to elaborate in the questionnaire.

\section{Discussion}

This study offers new knowledge in an area identified by only few studies and none similar to this one. The methods used in this project have been adequate and answered the study questions sufficiently, and the study benefits from the fact that the methods are complementary ${ }^{[8]}$. Saturation of data in the focus group interview compared with the qualitative statements in the questionnaire was found. The construction of the project group was based on the idea that different levels of experience in different settings of the nursing education could generate as many perspectives as possible, which has strengthened the analytical process. It would have been desirable to conduct interviews before the intervention and, especially after the intervention, with the clinical teachers. This is because it seems to be relatively easy to implement a structured tool among the students, but its adaption into the clinical teachers' practice has been minimal.

The response percentage was relatively high, and all the students and clinical teachers at the specific hospital were invited to participate. The nursing school at the University College Metropol, however, is the biggest nursing school in Denmark; and, normally, 110-150 students go out into clinical studies in module 4 every ten weeks, so the study could have been conducted in a larger setting, thereby providing results more sufficient on which to generalise.

This study shows that a pre-designed syllabus in the form of a template could affect how students benefit from their clinical studies. This might be because the individual syllabus invites the students to integrate their theoretical knowledge, practical skills, clinical reasoning and ethical stances - the four professional areas of learning according to Benner et al. ${ }^{[10]}$. Benner also states that a normal curriculum built upon technical skills and knowledge does not invite students to transform the four professional areas into a clinical context. In this project, it has become evident that, when the template for the individual syllabus works, the students actually get the ability to be creative in the way they transform knowledge and skills in a clinical setting in which they can then practice their reasoning and ethics. 
This study shows that working with a template helps the students because they do not have the knowledge or understand the extent of their possibilities. The individual syllabus may be compared to a learning contract, but it comprises objectives for the whole period and, therefore, its extent is greater. Learning contracts have been evaluated as a powerful approach to clinical assessment because they are able to capture the multidimensional nature of practice with the potential of integrating theory with practice ${ }^{[11]}$. The individual syllabus, however, is not an assessment tool but the student's own way of working with the curriculum. By using this tool, learning and assessment are not intended to be integrated. Rather it is a way of ensuring that the students cover the scope of the clinical period.

The reasons the clinical teachers have not been able to appreciate the value and clarity of the syllabus to the same extent as the students are still unclear. A study testing an assessment tool in clinical practice pointed to the fact that the nurses might experience ambiguity because their own lack of knowledge would be exposed ${ }^{[6]}$, but it is also of great importance to engage the clinical teachers more because feedback from teachers improves the student results ${ }^{[12]}$. Other studies have pointed to the fact that the clinical teachers' motivation, responsibility and enthusiasm need to be supported ${ }^{[13]}$, which is also what the students in this study call for.

This study also points to the fact that it is important in the future to look at and redefine how clinical teachers and theoretical teachers can and should use each other when it comes to integrating tools for study. In the setting described in this project, the demand and possibilities for theoretical teachers to have an impact were limited to one meeting during the 10-week period. Benner et al claim that it is of great importance that the collaboration between theoretical and clinical teachers must be strengthened if we want to integrate theory and practice to a greater extent ${ }^{[10]}$ and that an interaction and strong collaboration are needed between the parties to guarantee quality in the supervision of students ${ }^{[5,13]}$.

The project does not contribute knowledge as to the students' actual learning benefit from the individual syllabus, merely that the translation is easier. A structured method such as the individual syllabus could be classified as a way of trying to achieve what the revised Bloom's taxonomy calls meta-cognitive knowledge because the students gain insight into their own cognition and, at the same time, structure how they will gain factual, conceptual and procedural knowledge ${ }^{[14]}$.

It might be the case that many institutions with the responsibility for educating nurses actually work with concrete tools. However, our search for literature on the topic, national and international, has not revealed that these tools have actually been tested. One could speculate that many teachers and institutions within nursing education work with different concrete tools in the clinical setting but that these tools are experience-based and not validated as pedagogical tools. This is not necessarily a bad thing. However, if we want to appear stronger in our teaching practice, we should emphasize testing our methods and sharing knowledge - because we as teachers also need to translate our pedagogical knowledge into practice. This does not mean that our pedagogical practice should be standardized, only that it should be researched in a more structured manner.

This project has produced food for thought in our organization, especially because it is necessary in the future to look at more innovative and creative solutions as to how the students can learn in a clinical setting, where the demand for productivity is in constant focus, as others have pointed out ${ }^{[15]}$. Echoing the others, therefore, we recommend that the school and clinical setting improve their collaboration to facilitate an understanding of the learning objectives by using a template when putting together the individual syllabus.

\section{Conclusion}

This development project shows that using a template and an elaborate written explanation and spending a few hours on a general introduction with student involvement affect how nursing students perceive the purpose, value and sense of ownership of the individual syllabus positively, especially in terms of a translation of the learning objectives. This does not necessarily mean they learn more but that they find it easier to navigate in a clinical setting. Using templates as a tool is debatable in a pedagogical context, but this project shows that it has potential and that we should focus on a concrete 
evaluation of tools in the future because it looks as if it makes it easier for students to translate theory into practice, compared to a looser, more individualized pedagogical structure.

The project also points to the fact that we need to focus continuously on the collaboration of clinical and theoretical teacher, and the skills of clinical teachers should be intensified, developed and evaluated in the future because clinical teachers play an essential role in the clinical training of nursing students - especially, in the context of this project, with regard to the visibility of student goals in the ward and student motivation in the use of a mandatory individual syllabus.

\section{Acknowledgement}

The project was funded via globalization resources from the Metropolitan University College.

\section{References}

[1] Buckley, S. et al. The educational effects of portfolios on undergraduate student learning: A best evidence medical education (BEME) systematic review. Medical Teacher. 2009; 31: 282-298. PMid:19404891 http://dx.doi.org/10.1080/01421590902889897

[2] Ministry of Education. Act on Education of Bachelor of Science in Nursing. BEK 29 of 24/01/2008 (in Danish).

[3] Macnee CL, McCabe S. Understanding Nursing Research. Lippincott Williams \& Wilkins 2008.

[4] Allan, H.T., Smith, P. Are pedagogies used in nurse education research evident in practice? Nurse Education Today. 2000; 30: 476-479. PMid:19926366 http://dx.doi.org/10.1016/j.nedt.2009.10.011

[5] Newton, J.M., Billet, S., Jolly, B., Ockerby, C. Lost in translation: Barriers to learning in health professional clinical education. Learning in Health and Social Care. 2009; 8(4): 315-327. http://dx.doi.org/10.1111/j.1473-6861.2009.00229.x

[6] Ulfvarson, J., Oxelmark, L. Developing an assessment tool for intended learning outcomes in clinical practice for nursing students. Nurse Education Today. 2012; 32: 703-708. PMid:22051102 http://dx.doi.org/10.1016/j.nedt.2011.09.010

[7] Mathar, H. Drop-out and retention of nursing students in nursing education. Sygeplejersken 2011; 14:72-82 (in Danish, English abstract available).

[8] Polit, D.F., Beck, C.T. Nursing Research: Generating and Assessing Evidence for Nursing Practice. 8th edition, Lippincott Williams \& Wilkins.

[9] Malterud, K. Qualitative research: standards, challenges, and research. The Lancet. 2001; 11(358): 483-8. http://dx.doi.org/10.1016/S0140-6736(01)05627-6

[10] Benner, P., Sutphen, M., Leonard, V., Day, L. Educating Nurses: A Call for Radical Transformation. Akribe, 2010.

[11] Redfern, S. et al. Assessing competence to practice in nursing: a review of the literature. Research Papers in Education. 2002; 17(1): 51-77. http://dx.doi.org/10.1080/02671520110058714

[12] Fitgerald, M., Gibson, F., Gunn, K. Contemporary issues relating to assessment of pre-registration nursing students in practice. Nurse Education in Practice. 2010; 10: 158-163. PMid:19854679 http://dx.doi.org/10.1016/j.nepr.2009.06.001

[13] Löfmark et al. Supervising teachers' lived experience on supervision in teaching, nursing and social care education. A participation-oriented phenomenological study. High Educ. 2009; 57: 107-123. http://dx.doi.org/10.1007/s10734-008-9135-3

[14] Su, W.M., Osisek, P.J. The Revised Blooms's Taxonomy: Implications for Educating Nurses. The Journal of Continuing Education in Nursing. 2011; 42(7): 321-327. PMid:21707023 http://dx.doi.org/10.3928/00220124-20110621-05

[15] Messina, A.M., Steckel, A., Voelpel, P.A. A Pilot Program for Maximizing Faculty Productivity in the Clinical Setting. Nursing Education Perspectives. 2008; 29(4): 198-200. PMid:18770946 